\title{
Structural biology of presenilin 1 complexes
}

\author{
Yi Li', Christopher Bohm², Roger Dodd ${ }^{1}$, Fusheng Chen², Seema Qamar', Gerold Schmitt-Ulms², \\ Paul E Fraser ${ }^{2}$ and Peter H St George-Hyslop ${ }^{1,2^{*}}$
}

\begin{abstract}
The presenilin genes were first identified as the site of missense mutations causing early onset autosomal dominant familial Alzheimer's disease. Subsequent work has shown that the presenilin proteins are the catalytic subunits of a hetero-tetrameric complex containing APH1, nicastrin and PEN-2. This complex (variously termed presenilin complex or gamma-secretase complex) performs an unusual type of proteolysis in which the transmembrane domains of Type I proteins are cleaved within the hydrophobic compartment of the membrane. This review describes some of the molecular and structural biology of this unusual enzyme complex. The presenilin complex is a bilobed structure. The head domain contains the ectodomain of nicastrin. The base domain contains a central cavity with a lateral cleft that likely provides the route for access of the substrate to the catalytic cavity within the centre of the base domain. There are reciprocal allosteric interactions between various sites in the complex that affect its function. For instance, binding of Compound E, a peptidomimetic inhibitor to the PS1 N-terminus, induces significant conformational changes that reduces substrate binding at the initial substrate docking site, and thus inhibits substrate cleavage. However, there is a reciprocal allosteric interaction between these sites such that prior binding of the substrate to the initial docking site paradoxically increases the binding of the Compound E peptidomimetic inhibitor. Such reciprocal interactions are likely to form the basis of a gating mechanism that underlies access of substrate to the catalytic site. An increasingly detailed understanding of the structural biology of the presenilin complex is an essential step towards rational design of substrate- and/or cleavage site-specific modulators of presenilin complex function.
\end{abstract}

Keywords: Presenilin, Nicastrin, APH1, PEN-2, Gamma-secretase, Epsilon secretase, Notch, APP, Abeta, Structural biology, Gamma-secretase inhibitor compounds, Gamma-secretase modulator compounds, Lateral gate

\section{Introduction}

Multiple lines of evidence suggest that the accumulation and aggregation/oligomerisation of the $\mathrm{A} \beta$ peptide plays a central role in the pathogenesis of Alzheimer's disease (AD). $A \beta$ is derived from the amyloid precursor protein (APP) after sequential cleavage of APP. In the first step of the amyloidogenic pathway, APP is cleaved by BACE1 to generate a soluble $\mathrm{N}$-terminal fragment $(\beta$ sAPP) and a membrane-bound $C$-terminal fragment, C99. The C-terminal fragment is then cleaved through its transmembrane domain by the presenilin complex, thereby generating a series of proteolytic fragments that include $A \beta$ peptides (released into the lumen) and amyloid intracellular domain (AICD, released into the

\footnotetext{
* Correspondence: p.hyslop@utoronto.ca

'Cambridge Institute for Medical Research, Wellcome Trust MRC Building, Addenbrookes Hospital, Hills Road, Cambridge CB2 OXY, UK

${ }^{2}$ Tanz Centre for Research in Neurodegenerative Diseases and Depts of Medicine, Laboratory Medicine and Pathobiology and Medical Biophysics, University of Toronto, Krembil Discovery Tower, 6th Floor- 6KD417, 60 Leonard Avenue, Toronto, Ontario M5T 2S8, Canada
}

(c) 2014 Li et al.; licensee BioMed Central. This is an Open Access article distributed under the terms of the Creative Commons Attribution License (http://creativecommons.org/licenses/by/4.0), which permits unrestricted use, distribution, and reproduction in any medium, provided the original work is properly credited. The Creative Commons Public Domain Dedication waiver (http://creativecommons.org/publicdomain/zero/1.0/) applies to the data made available in this article unless otherwise stated. cytosol) [1-8] (Figure 1). A $\beta$ peptides so produced are of various lengths and differing abundance, but the principal species is $A \beta 40$, with lesser amounts of $A \beta 42$. The proteolytic cleavage of the C99 membrane-bound stub begins at the cytoplasmic face with the initial cleavage, termed $\varepsilon$ cleavage. The $\varepsilon$-cleavage occurs at residue 49 relative to the BACE cleavage site, just inside the inner membrane leaflet [3,5,6,9-11]. A second set of cleavages occur at residue 46, termed, the $\zeta$-cleavage site [12], producing $\mathrm{A} \beta 46$ plus a small labile C-terminal fragment $[3,13,14]$. The final cleavage occurs at the $\gamma$-cleavage site at residue 40, yielding A $\beta 40$ (Figure 1). However, minor sets of cleavages give rise to other fragments, for instance $A \beta 48(\varepsilon), A \beta 45(\zeta)$ and $A \beta 42(\gamma)$, which represent products of cleavages on the opposite face of the TM helix [11,15-18]. Related $\varepsilon$ - and $\gamma$ cleavage sites have been identified during Notch-1 cleavage, but are named as S3 and S4 cleavages, respectively [19].

$\mathrm{A} \beta$ peptides of different length have differing propensities to aggregate or to cause neurotoxicity [20]. Consequently, 


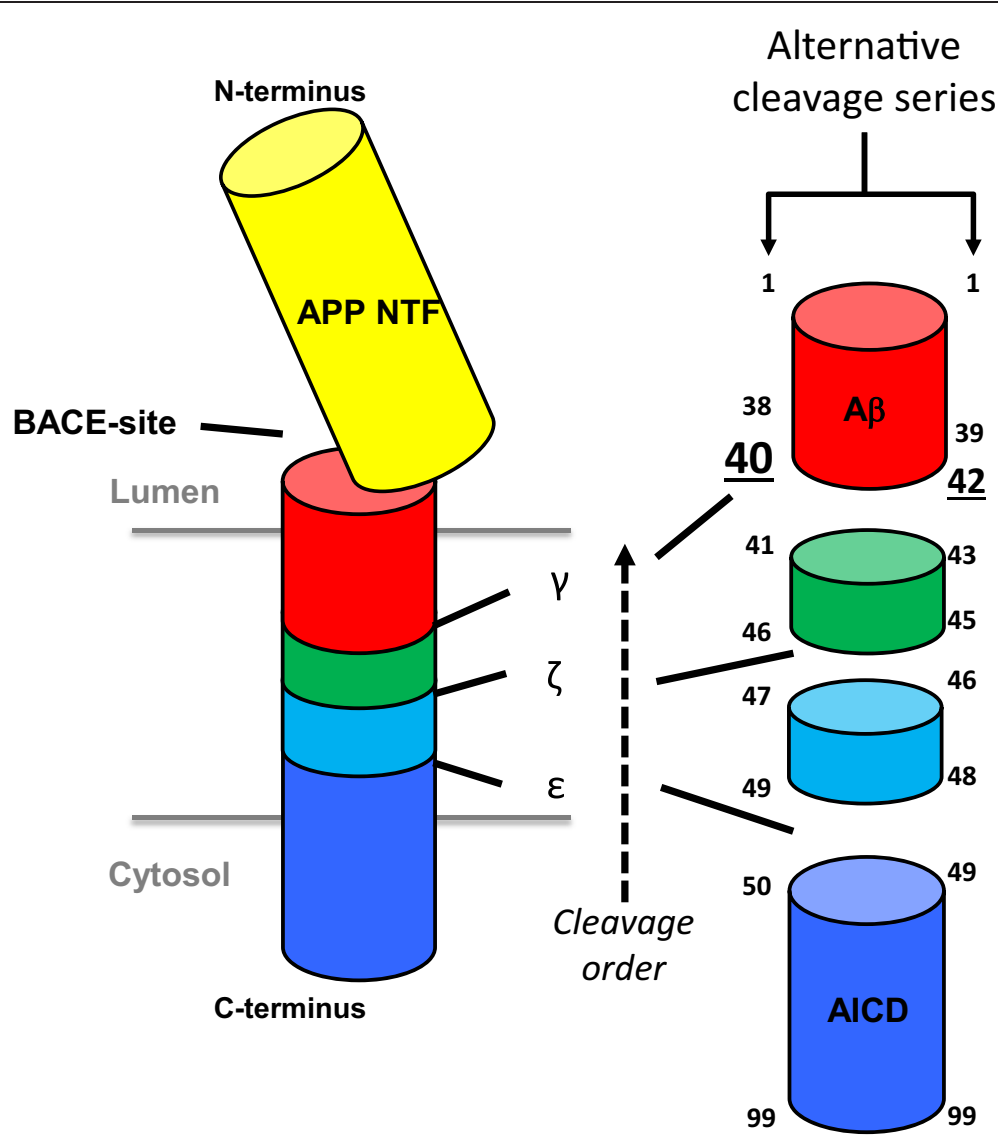

Figure 1 Sequential cleavage sites on APP involved in the $\beta$-amyloid producing pathway. Multiple species of A $\beta$ can be produced. The most prevalent species end at residue 40 , but species ending at residue 42 , 38 etc. are also generated. Species ending at residue 42 are particularly prone to oligomerization.

it has been proposed that therapeutic manipulation of $A \beta$ neurotoxicity could be achieved either by inhibiting total $A \beta$ production or by modulating the specific $A \beta$ species produced [21-24]. Recent work with gamma-secretase modulator (GSM) compounds has highligted the difficulty in generating substrate-specific inhibitors that potently prevent the generation of amyloidogenic APP cleavage products but exhibit minimal activity toward the cleavage of other substrates such as Notch-1. Even semi-specific compounds, including semagacestat, inhibit the cleavage of non-APP target substrates to a degree that causes unacceptable side effects $[25,26]$. This review examines the function of the presenilin complexes from a structural perspective and emphasizes aspects of their biology that will need to be understood before rational drug design approaches can be applied to achieve either improved substrate specificity and/or to modulate the species of $A \beta$ produced.

\section{Presenilin complexes}

The presenilin (PS) genes were first identified by this group during searches for genes responsible for early onset familial AD (FAD), [27,28]. There are two presenilin genes in vertebrates: PSEN1 (on chromosome 14, encodes PS1) and PSEN2 (on chromosome 1, encodes PS2). Both PS1 and PS2 are $\sim 50 \mathrm{kDa}$ polytopic transmembrane proteins that interact with nicastrin, PEN-2 and APH1, to form the biologically active $\gamma$-secretase [29-35] (Figure 2). The assembly of these four components to a functional $\gamma$-secretase complex is tightly controlled and gives rise to a 1:1:1:1 heterotetrameric complex with a mass of $174 \mathrm{kDa}$, as determined by SEC-MALS [36]. $\gamma$-secretase complexes lacking any of their subunits are destabilised and degraded [37].

\section{Topology and structure of presenilin 1 complex components \\ Presenilin}

PS1 (and PS2) are the catalytic subunits of the heterotetrameric presenilin 1 (or presenilin 2) complexes [29,31] and are the archetypal members of the GXGD family of intramembranous aspartyl proteases, which also includes signal peptide peptidases (SPP) and a variety of archaeal homologues [38-42]. 


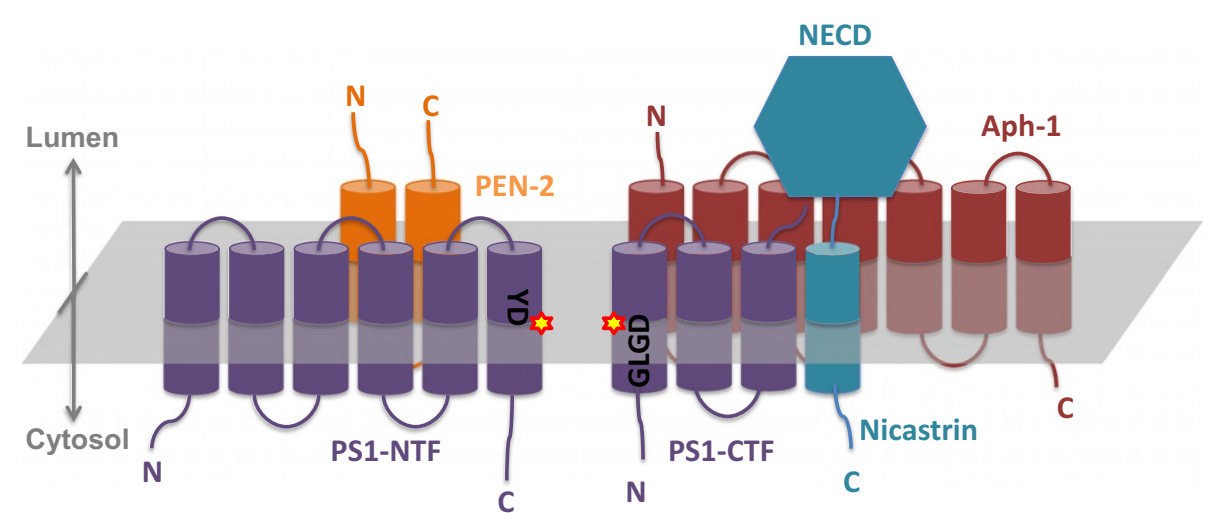

Figure 2 Topology view of presenilin 1 complex subunits: presenilin (purple), nicastrin (blue), Aph1 (red) and PEN-2 (orange). The highly conserved sequence in the catalytic pocket, YD287 and GLGD385 (presenilin 1 numbering), has been specified with stars.

During the assembly and maturation of presenilin complexes, the PS1 or PS2 subunits undergo endoproteolytic cleavage into N- and C-terminal fragments [37,43,44]. For PS1 the cleavage occurs near residue Met298 (encoded by Exon9) within a cytoplasmic peptide loop encoded by Exon 8-10 [45].

Presenilin proteins adopt a membrane topology characterized by nine helical transmembrane (TM) domains. Once folded, its hydrophilic, flexible $\mathrm{N}$-terminus is located in the cytosol. In contrast, its C-terminus is either embedded within the lumenal face of the lipid bilayer or protrudes into the lumen or extracellular space [46-49]. Crosslinking experiments using a series of TMD-swap PS1 mutants revealed that TM2 and TM6 are both in proximity to TM9 [50]. TM6 and TM7 each contain one of two aspartyl residues required for catalytic activity [31]. A solution state NMR structure of the PS1-CTF domain is available that was generated by using a cellfree expression system and SDS micelles for embedding the protein [51] (PDB code 2kr6). This model confirmed the prediction that TM7, TM8 and TM9 are likely to be helical and also revealed a small helix within the domain encoded by Exon 9. However, the results are difficult to interpret, given the solubilization of the protein fragment in SDS micelles, which may exert different constraints on protein folding than the lipid bilayer, and the absence of PS1-NTF and other presenilin subunits.

More recently, a crystal structure has been reported for a distant homologue of PS1 from the archaeon Methanoculleus marisnigri JR1 (MCMJR1) [52]. Like the human PS1 protein, this archaeal protein adopts a membrane topology that comprises nine transmembrane segments (TMs) and cleaves itself into $\mathrm{N}$-terminal (encompassing TMs 1-6) and C-terminal (encompassing TMs 7-9) fragments, each of which contains a catalytic aspartate residue. The crystal structure of MCMJR1 reveals a protein fold in which the $\mathrm{N}$-terminal domain wraps around the C-terminal domain positioned in the center of the structure. The two catalytic aspartate residues in the structure are observed not to be in close enough proximity in order for catalysis to occur. Indeed, the particular construct used in crystallisation, which has had a large section of the loop between TM6 and 7 proteolytically removed, is inactive (unpublished observations). The authors suggest a possible route for substrate access between TM6, TM7, and TM8. However, in the structural model presented the route appears to be almost entirely obstructed.

\section{Nicastrin}

Nicastrin was the first subunit of the complex to be cloned after the presenilins [35]. Nicastrin consists of a transmembrane helical domain and an extracellular glycosylated ectodomain. Nicastrin may be involved in regulating intracellular protein trafficking of the nascent presenilin complex during its assembly [53-55] and in binding to the $\mathrm{N}$-terminus of substrates $[56,57]$. Nicastrin associates with the hemicomplex comprising PS1-CTF and APH1 by binding to the the C-terminus of PS1 [58].

Nicastrin is a type I integral membrane protein and contains a conserved DYIGS motif that may be involved in substrate binding. The ectodomain of Nicastrin has been predicted to adopt an aminopeptidase/transferrin receptor-like secondary structure [59]. Indeed, due to considerable sequence similarities between the Nicastrin ectodomain (NECD) and both the human transferrin receptor (PDB code 1cx8) and the glutamate carboxyl peptidase PSMA (PDB code 2xef), the structure of the nicastrin ECD could be modelled using the X-ray crystal structures of these proteins as a template. This structural homology was recently confirmed in a cryo-EM study [60] (PDB 4upc) and by crystallography [61] (PDB 4r12). Prior to the atomic structures of NECD $[60,61]$, other structural studies had predicted additional structural domains downstream of the DYIGS motif and peptidaselike domains, near residue 571 . This domain was initially predicted to be homologous to tetratricopeptide repeat 
(TPR) domains, which are commonly involved in peptide recognition [62]. However, a TPR fold was not apparent in the atomic structures of NECD, which contained most of this domain [60,61].

The function of the NECD is currently the focus of some controversy. The NECD carries extensive glycosylation (potentially 16 sites, with $\sim 36 \mathrm{kDa}$ total mass) and adopts a thermostable structure [63]. The presence of non-functional peptidase domain in the NECD, together with observations that indicate nicastrin detects the lengths of extracellular N-terminal protrusions of substrate proteins, suggest it may be involved in substrate selection and acquisition [57]. However, nicastrin is not essential for $\gamma$-secretase activity [64].

\section{PEN-2}

PEN-2 and the fourth component of the complex, $\mathrm{APH} 1$, were both identified and cloned by genetic screens in invertebrates for enhancers and suppressors of Notch signaling [65] PEN-2 is a 101 residue (12 kDa) membrane protein with two predicted transmembrane domains. By introducing N-linked glycosylation sites into the $\mathrm{N}$ - and $\mathrm{C}$-termini or the loop region between the two putative transmembrane helices of PEN-2, it has been possible to show that both termini of this protein are luminal, while the hydrophilic loop is cytosolic [66]. PEN-2 binds to the fourth transmembrane domain of PS1 [67-69] and helps to stabilise the $\gamma$-secretase complex after PS1 endoproteolysis [70]. PEN-2 is also suggested to play an essential but as yet poorly understood role in the final assembly step and activation of the mature complex [71].

\section{APH1}

Anterior Pharynx Defective 1 (APH1) is a protein of approximately 308 amino acids in C. elegans and 195-265 residues in mammals [65]. In humans, two paralogous genes, which map to Chromosomes 1 and 15, encode for the highly similar gene products APH1A and APH1B, respectively. A further duplication of the APH1B gene in mice gave rise to a third APH1 family gene, APH1C. Because only one copy of any of the available APH1 proteins is incorporated into a given presenilin complex, two different types of PS1 or PS2 complex are observed in humans, and three different types of PS1 or PS2 complex exist in mice [72]. The function of APH1 is still not well established, although it is clear that APH1 is required for $\gamma$-secretase activity. All human and mouse APH1 paralogs contain a conserved GXXXG motif that may be involved in interactions with other subunits in the presenilin complex [73]. The membrane topology of APH1 has been studied by selective permeabilization of the plasma membrane and immunofluorescence microscopy, which revealed that the protein is a multi-pass transmembrane protein with its C-terminus facing the cytosol. More detailed glycosylation mutagenesis experiments further revealed APH1 to acquire a seventransmembrane topology with its N-terminus, as well as even-numbered loops, facing the lumen [74]. Several studies have shown that APH1 and nicastrin form a stable sub-complex [75,76]. It has been suggested that the APH1:nicastrin complex forms an initial scaffold prior to the generation of the full presenilin complex $[7,8,55,77,78]$. As the assembly of the presenilin complex progresses the PS1-CTF subunit joins this initial scaffolding complex by an interaction between the extreme PS1 C-terminus and APH1 [58].

\section{Structure of presenilin complex: early globular models}

Obtaining both static and dynamic structural models of the presenilin complex is an important step towards understanding how the complex works. Electron microscopybased structural investigations of the presenilin complexes are non-routine and difficult due to its low molecular weight and lack of symmetry. Prior to 2014 [79-82], electron microscopy reconstruction studies generated a variety of 3D structure models differing in shape and volume. None of these were validated using independent biophysical methods. The first of these early models used negative stain electron microscopy to reveal a flat heart-shaped model resolved at $48 \AA$ and exhibiting C2 symmetry [82]. The presenilin complex occupied a volume of $560 \AA \times$ $320 \AA \times 240 \AA$ in this structural model. Afterwards, three more low resolution structure models were generated by negative stain or cryo-electron microscopy for PS1 complexes isolated in CHAPSO or digitonin [79-81]. The first of these was a $20 \AA$ resolution globular structure model with a $120 \AA$ diameter and a $20-40 \AA$-wide low density chamber. The model proposed openings at both the top and bottom surfaces [80] and attributed a small protrusion to represent the NECD. This model was then improved to a $12 \AA$ cryo-electron microscopy model with a globular structure, dimensions of $80 \AA \times 90 \AA \times 85 \AA$ and three solvent-accessible but non-perforating central cavities in the membrane-embedded domain [81]. The third globular model was based on cryo-EM data with $18 \AA$ resolution, and depicted the presenilin complex with a cup-like shape and a lateral belt surrounding a water-accessible internal chamber. Based upon labeling experiments that made use of a $\gamma$-secretase transition state inhibitor coupled to gold particles, the catalytic site was thought to be located in this chamber. A structure model of a pre-activation, PEN-2-free complex was also built in this study. Comparisons between the pre-activation model and the model of the mature complex suggested that PEN-2 binding modifies the architecture of the active site during complex maturation [79]. 
Structure of presenilin complex: recent bi-lobed models

Early in 2014, a considerable advance in the structural modeling of the presenilin complex was achieved when negative stain 3D electron microscopy data were combined with several complementary cross-validating biochemical, pharmacological and biophysical methods including SEC-MALLS and FRET-FLIM [36]. The study provided an experimentally-validated structure and generated the first direct visualization of a structurally dynamic presenilin complex. Structures were built at $17 \AA$ using single particle electron microscopic methods for both the native human PS1 complex and for the human PS1 complex following the binding of the non-transition state peptidomimetic $\gamma$-secretase inhibitor Compound E ((S,S)- 2-[2-(3,5-Difluorophenyl)-acetylamino]-N-(1methyl-2-oxo-5-phenyl-2,3-dihydro-1H-benzo[e] [1,4] diazepin-3-yl)-propionamide, M.W. = 490.5 Da). In contrast to the globular shape predictions of earlier models, this work proposed that presenilin complexes have a bi-lobed shape, containing a larger base (93 $\AA$ ×93 $\mathrm{\AA}$ $60 \AA$ ) and a separate, smaller head ( $65 \AA \times 60 \AA \times 55 \AA$ ) (Figure 3A). The orientation of the complex was determined by immuno-labelling the $\mathrm{N}$-terminus of nicastrin (residues 168-289), which demonstrated that the nicastrin ectodomain is located in the head domain of the bi-lobed complex (Figure 3A). In good agreement with this conclusion, the height of the base domain in this model is approximately $60 \AA$, which is sufficient to span the widths of most cellular membranes (35-40 ̊) [83,84] and, thus, large enough to contain the TM domains of PS1, PEN2, APH1, and NCT.

In partial agreement with some of the earlier models, this first bi-lobed model displayed a central cavity in the base domain that opens toward the lumenal/extracellular surface (Figure 3A). Crucially, the base domain contained a lateral cleft that communicated with the central cavity. This cleft was suggested to be part of a lateral gate mechanism involved in substrate access because it was closed by binding of Compound E, which blocks substrate binding to the Initial Substrate Docking site [36].

More recently, considerable advances in cryo-EM technology, in particular the use of new detectors and image processing methods, enabled further refinements of this model by increasing the image resolution to $4.5 \AA$ [60] (EMD-2677, PDB code 4upc). This higher resolution model confirmed the bi-lobed shape of human presenilin complexes as their native state (Figures $2 \mathrm{~B}$ and $3 \mathrm{~B}$ ). Multiple transmembrane helices were also visible in this new model but the resolution remained insufficient to assign individual TMs to specific subunits of the complex (Figure 3B).

\section{Subunit interaction and domain movement in the PS1 complex Inhibitor-induced conformational change}

The presence of certain detergents causes a concentrationdependent dissociation of the presenilin complex into two hemi-complexes $[36,85,86]$. Each hemicomplex contains one catalytic aspartate of the presenilin protein. One of the hemi-complexes consists of PS1-NTF and PEN2, while the other hemi complex consists of nicastrin, APH1 and PS1-CTF (Figure 2). Interestingly, inhibitors, such as Compound E, can stabilise the PS1 complex and prevent its detergent-induced dissociation [36]. This result suggests that inhibitor binding causes a conformational change that brings the complex components closer together. Such a conformational change would lead to the formation of
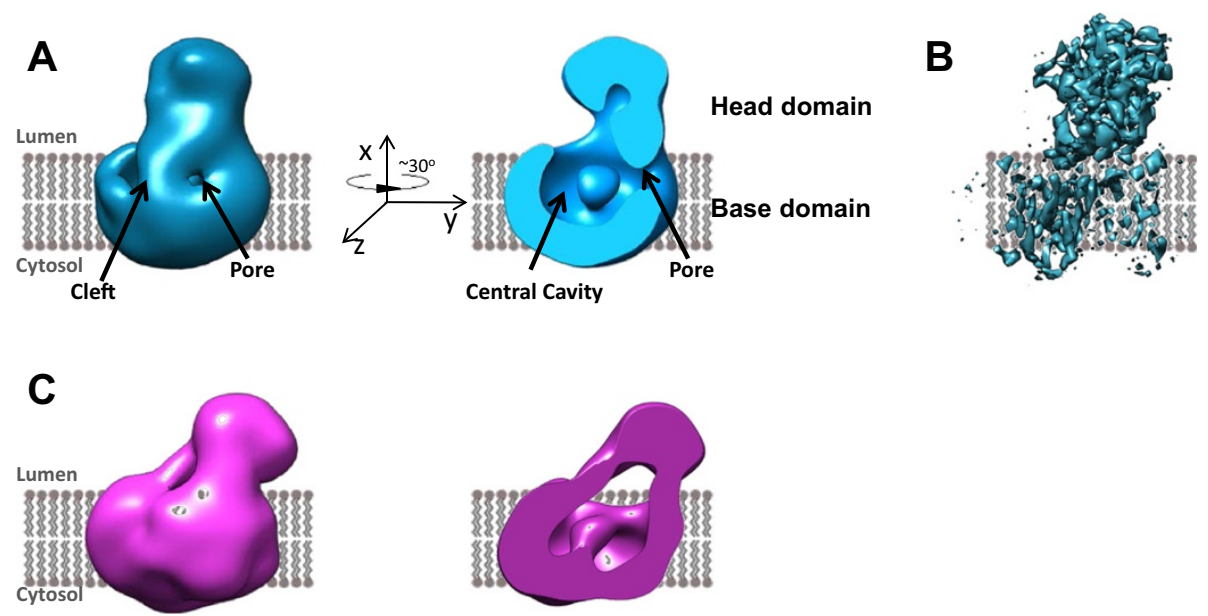

With inhibitor CpdE bound

Figure 3 Bi-lobed models of presenilin 1 complex by electron microscopy. (A) The first bi-lobed structure model of PS1 complex, 14.7 using negative stain EM (EMD-2477). (B) The $4.5 \AA$ model of PS1 complex by cryo-EM (EMD-2677), confirming its bi-lobed shape. (C) $14.7 \AA$ model of PS1 complex bound with its non-transition state inhibitor Compound E (CpdE) (EMD-2478). This model revealed a conformational change induced by the inhibitor. 
new interactions between the hemi-complexes, resulting in an overall stabilisation of the complex.

This long-range conformational change in the complex was confirmed indirectly by in vitro intra-molecular Fluorescent Lifetime Imaging Microscopy - Förster Resonance Energy Transfer methods (FLIM-FRET) in which a donor GFP tag was added to the N-terminus of PS1-NTF and a acceptor RFP tag was cloned into the loop at the $\mathrm{N}$ terminus of PS1-CTF. In the presence of Compound E, there was a significant change in FRET-FLIM, indicating that the two $\gamma$-secretase hemicomplexes have been brought closer together by Compound E binding [36].

These indirect experiments were then directly confirmed by negative stain single particle electron microscopy.

The EM structure model for Compound E-bound PS1 complexes was highly similar to the native complexes with a bi-lobed overall shape. However, there were several critical differences. Following binding of Compound $\mathrm{E}$ to a non-catalytic site on PS1-NTF, PS1 complexes undergo several allosteric conformational changes that include: 1) rotation of the nicastrin-containing head domain; and 2) compaction of the membrane embedded base domain with closure of the lateral cleft (Figure 3C) [36].

\section{Reciprocal cross-talk between the initial substrate docking site and the inhibitor binding site}

Excitingly, the Li et al. study also revealed that there are several reciprocal long range interactions between the initial substrate docking site at the interface between the PS1-NTF and PS1-CTF and the Compound E binding site. Specifically, substrate docking increases inhibitor binding [36]. Conversely, Compound E binding induced a dosedependent reduction in substrate binding.

These observations not only demonstrate that the presenilin complex is structurally dynamic, they show for the first time that there are important reciprocal long-range

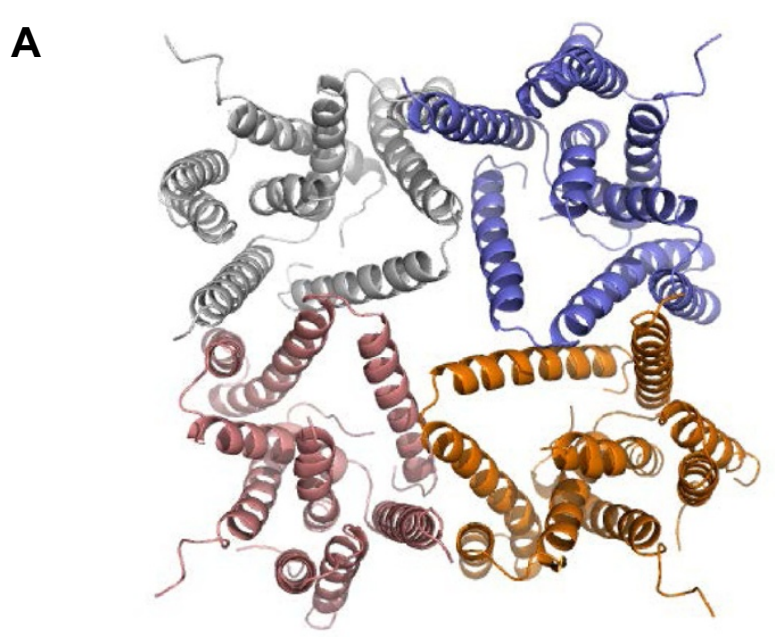

B

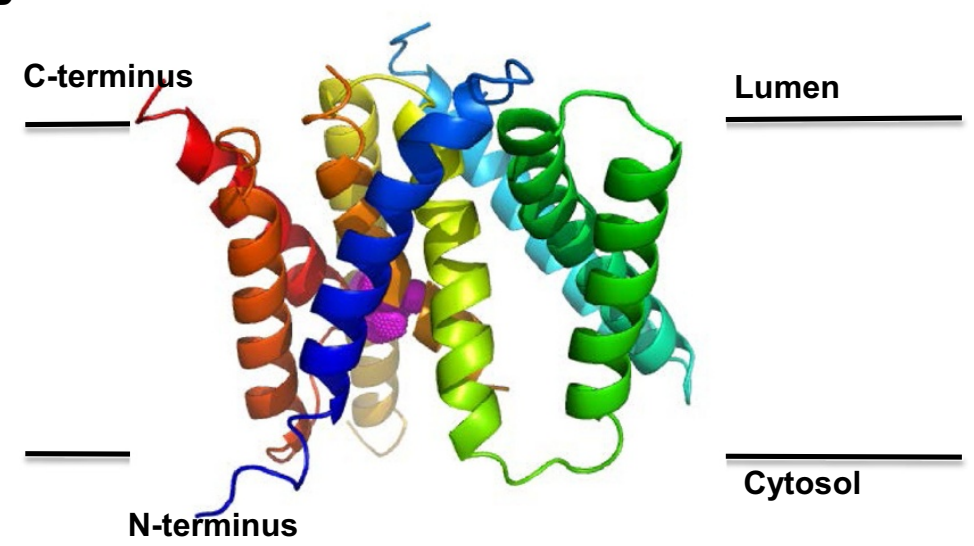

Figure 4 Structure of presenilin protein homologue, SPP. (A) Crystallographic tetramer of MCMJR1 (PDB 4hyc). The image is generated by PyMOL and coloured to emphasize different domains. (B) Rainbow coloured (The PyMOL Molecular Graphics System, LLC) MCMJR1 monomer structure (PDB 4hyc, chain A). The active site (magenta) is buried within a hydrophilic pocket between TM domains. 
structural interactions occurring between different sites within the complex. These findings shed light on how non-catalytic site inhibitors might work (namely by allosterically closing the substrate docking site). Importantly, these findings also provide a testable hypothesis on how a series of reciprocal allosteric interactions could operate a lateral gate governing substrate access to the protected catalytic pocket. Thus, binding of substrate at the initial docking site might open a translocation pathway to permit movement of the substrate into the complex. Subsequent occupancy of sites (e.g. the site of binding by the peptidemimetic Compound $\mathrm{E}$ inhibitor) in the translocation pathway might then close the initial docking site, until the substrate is cleaved. At that point, release of the reaction products relaxes the closure of the initial docking site and the enzyme can reconfigure to bind a new substrate molecule. Such a mechanism would account for the slow processivity of presenilin complexes.

\section{Structure of presenilin-like homologues}

Signal peptide peptidases (SPP) form a family of intramembranous aspartyl proteases homologous to presenilins. The negative stain EM-based structure of human SPP was determined at $22 \AA$ resolution [87]. The model revealed SPP as a slender, bullet-shaped homotetramer. Independent biochemical studies have also suggested that a homotetrameric complex may be the functional unit of SPP. The SPP EM model displayed a central chamber possibly analogous to the central chamber/cleft observed in the presenilin archeal homologues (see next paragraph) [87].

More recently, in 2013, a $3.3 \AA$ crystal structure of the archeal GXGD presenilin-like aspartyl protease MCMJR1 (also known as mmPSH, PDB code 4hyc, 4hyd and 4hyg) (Figure 4A) revealed that the active site of MCMJR1 is buried in a hydrophilic pocket formed by the TM domains [52] (Figure 4B). A lateral cleft between TM6 (located on PS1-NTF in PS1) and TM9 (on PS1-CTF in PS1) and a central channel was proposed as a potential route for substrate access, although closer inspection reveals the cleft between TM6 and TM9 to be occluded in the crystal structure [52]. It is unclear whether this is: 1) an artefact of the mutagenesis required to get the protein to crystallise; 2) a packing artefact during crystallization; or 3) the correct structure. Whether the substrate accesses via a route between TM6 and TM9 as suggested by some crosslinking studies therefore remains unresolved.

\section{Conclusions}

The recent structural studies on presenilin complexes represent a major advance toward the overall objective of understanding the molecular workings of the complex. The initial controversy surrounding the complex's overall shape has been put to an end by the consistent documentation of a bi-lobed structure in the most recent models. This bi-lobed model was carefully validated by multiple independent methods and has since been further confirmed by higher resolution cryo-EM data. The head domain of the bi-lobed shape contains the NECD, and the base domain contains the transmembrane domains of all four subcomponent proteins. The head domain rotates when Compound $\mathrm{E}$ inhibitor is bound to the complex. In its native state the base domain adopts an "open" structure with a central cavity and lateral cleft opening to the side. Compound E binding is associated with a "closed" conformation.

The next steps for the field will be to build structural models of the complex associated with various interaction partners, inhibitors and modulators. These models will facilitate a mechanistic understanding of all intramembranous aspartyl proteases. Importantly, by mapping the binding site of different classes of GSM and GSI compounds, and by the defining the consequent three dimensional structural shifts in the architecture of the complex, it may be possible to design compounds targeting specific substrates and/or specific cleavage products.

\section{Abbreviations}

PS1: Presenilin 1; PS2: Presenilin 2; APH1: Anterior pharynx 1; PEN-2: Presenilin enhancer 2; GSI: Gamma-secretase inhibitor compounds; GSM: Gamma-secretase modulator compounds; cryo-EM: Cryo- electron microscopy; SEC-MALS: Size exclusion chromatography multi angle light scattering; FRET FLIM: Förster resonance energy transfer fluorescence lifetime imaging; SPP: Signal peptide peptidase; MCMJR1: Clone name for Archeal presenilin-like homologue.

\section{Competing interests}

The authors declare that they have no competing interests.

\section{Author contributions}

All authors contributed to the generation of this review manuscript. All authors have also contributed the generation of primary research data that is published elsewhere and is reviewed in this manuscript. All authors read and approved the final manuscript.

\section{Acknowledgements}

This work was supported by grants in aid-of-research from the Canadian Institutes of Health Research, Wellcome Trust, Medical Research Council,

National Institutes of Health Research, and the Alzheimer Society of Ontario

Received: 7 November 2014 Accepted: 12 December 2014 Published: 18 December 2014

\section{References}

1. De Strooper B, Iwatsubo T, Wolfe MS: Presenilins and gamma-secretase: structure, function, and role in Alzheimer disease. Cold Spring Harb Perspect Med 2012, 2:a006304

2. Li H, Wolfe MS, Selkoe DJ: Toward structural elucidation of the gammasecretase complex. Structure 2009, 17:326-334.

3. Haass C, Kaether C, Thinakaran G, Sisodia S: Trafficking and proteolytic processing of APP. Cold Spring Harb Perspect Med 2012, 2:a006270.

4. Wolfe MS: Processive proteolysis by gamma-secretase and the mechanism of Alzheimer's disease. Biol Chem 2012, 393:899-905.

5. Chow WW, Mattson MP, Wong PC, Gleichmann M: An overview of APP processing enzymes and products. Neuromolecular Med 2010, 12:1-12.

6. Weidemann A, Eggert S, Reinhard FB, Vogel M, Paliga K, Baier G, Masters CL, Beyreuther K, Evin G: A novel epsilon-cleavage within the transmembrane domain of the Alzheimer amyloid precursor protein demonstrates homology with notch processing. Biochemistry 2002, 41:2825-2835. 
7. Yang DS, Tandon A, Chen F, Yu G, Yu H, Arawaka S, Hasegawa H, Duthie M, Schmidt SD, Ramabhadran TV, Nixon RA, Mathews PM, Gandy SE, Mount HT, St George-Hyslop P, Fraser PE: Mature glycosylation and trafficking of nicastrin modulate its binding to presenilins. J Biol Chem 2002, 277:28135-28142.

8. Gu Y, Chen F, Sanjo N, Kawarai T, Hasegawa H, Duthie M, Li W, Ruan X, Luthra A, Mount HT, Tandon A, Fraser PE, St George-Hyslop P: APH-1 interacts with mature and immature forms of presenilins and nicastrin and may play a role in maturation of presenilin-nicastrin complexes. J Biol Chem 2003, 278:7374-7380.

9. Fuwa H, Takahashi Y, Konno Y, Watanabe N, Miyashita H, Sasaki M, Natsugari $H$, Kan T, Fukuyama T, Tomita T, Iwatsubo T: Divergent synthesis of multifunctional molecular probes to elucidate the enzyme specificity of dipeptidic gamma-secretase inhibitors. ACS Chem Biol 2007, 2:408-418.

10. Tomita T, Iwatsubo T: Structural biology of presenilins and signal peptide peptidases. J Biol Chem 2013, 288:14673-14680.

11. Takami M, Nagashima $Y$, Sano $Y$, Ishihara S, Morishima-Kawashima M Funamoto $S$, Ihara $Y$ : gamma-Secretase: successive tripeptide and tetrapeptide release from the transmembrane domain of beta-carboxyl terminal fragment. J Neurosci 2009, 29:13042-13052.

12. Zhao G, Mao G, Tan J, Dong Y, Cui MZ, Kim SH, Xu X: Identification of a new presenilin-dependent zeta-cleavage site within the transmembrane domain of amyloid precursor protein. J Biol Chem 2004, 279:50647-50650.

13. Zhao G, Cui MZ, Mao G, Dong Y, Tan J, Sun L, Xu X: Gamma-cleavage is dependent on zeta-cleavage during the proteolytic processing of amyloid precursor protein within its transmembrane domain. J Biol Chem 2005, 280:37689-37697.

14. Zhao G, Tan J, Mao G, Cui MZ, Xu X: The same gamma-secretase accounts for the multiple intramembrane cleavages of APP. J Neurochem 2007, 100:1234-1246.

15. Matsumura N, Takami M, Okochi M, Wada-Kakuda S, Fujiwara H, Tagami S, Funamoto S, Ihara Y, Morishima-Kawashima M: gamma-Secretase associated with lipid rafts: multiple interactive pathways in the stepwise processing of beta-carboxyl-terminal fragment. J Biol Chem 2014, 289:5109-5121.

16. Okochi M, Tagami S, Yanagida K, Takami M, Kodama TS, Mori K, Nakayama $\mathrm{T}$, Ihara $Y$, Takeda M: gamma-secretase modulators and presenilin 1 mutants act differently on presenilin/gamma-secretase function to cleave Abeta42 and Abeta43. Cell Rep 2013, 3:42-51.

17. Takamura A, Kawarabayashi T, Yokoseki T, Shibata M, Morishima-Kawashima M, Saito Y, Murayama S, Ihara Y, Abe K, Shoji M, Michikawa M, Matsubara E: Dissociation of beta-amyloid from lipoprotein in cerebrospinal fluid from Alzheimer's disease accelerates beta-amyloid-42 assembly. J Neurosci Res 2011, 89:815-821.

18. Mori K, Okochi M, Tagami S, Nakayama T, Yanagida K, Kodama TS, Tatsumi S, Fujii K, Tanimukai H, Hashimoto R, Morihara T, Tanaka T, Kudo T, Funamoto S, Ihara Y, Takeda M: The production ratios of AICDepsilon51 and Abeta42 by intramembrane proteolysis of betaAPP do not always change in parallel. Psychogeriatrics Off J Japanese Psychogeriatric Soc 2010, 10:117-123.

19. Okochi M, Steiner H, Fukumori A, Tanii H, Tomita T, Tanaka T, Iwatsubo T, Kudo T, Takeda M, Haass C: Presenilins mediate a dual intramembranous gamma-secretase cleavage of Notch-1. Embo J 2002, 21:5408-5416.

20. Mucke L, Selkoe DJ: Neurotoxicity of Amyloid beta-Protein: Synaptic and Network Dysfunction. Cold Spring Harb Perspect Med 2012, 2:a006338.

21. Kounnas MZ, Danks AM, Cheng S, Tyree C, Ackerman E, Zhang X, Ahn K Nguyen P, Comer D, Mao L, Yu C, Pleynet D, Digregorio PJ, Velicelebi G, Stauderman KA, Comer WT, Mobley WC, Li YM, Sisodia SS, Tanzi RE, Wagner SL: Modulation of gamma-secretase reduces beta-amyloid deposition in a transgenic mouse model of Alzheimer's disease. Neuron 2010, 67:769-780.

22. Hall A, Patel TR: gamma-Secretase modulators: current status and future directions. Prog Med Chem 2014, 53:101-145.

23. Pettersson M, Stepan AF, Kauffman GW, Johnson DS: Novel gammasecretase modulators for the treatment of Alzheimer's disease: a review focusing on patents from 2010 to 2012. Expert Opin Ther Pat 2013, 23:1349-1366

24. Golde TE, Koo EH, Felsenstein KM, Osborne BA, Miele L: gamma-Secretase inhibitors and modulators. Biochim Biophys Acta 1828, 2013:2898-2907.

25. Imbimbo BP, Giardina GA: gamma-secretase inhibitors and modulators for the treatment of Alzheimer's disease: disappointments and hopes. Curr Top Med Chem 2011, 11:1555-1570.
26. Cummings J: What can be inferred from the interruption of the semagacestat trial for treatment of Alzheimer's disease? Biol Psychiatry 2010, 68:876-878.

27. Sherrington $R$, Rogaev El, Liang $Y$, Rogaeva $E A$, Levesque $G$, Ikeda $M, C h i H$, Lin C, Li G, Holman K, Tsuda T, Mar L, Foncin JF, Bruni AC, Montesi MP Sorbi S, Rainero I, Pinessi L, Nee L, Chumakov I, Pollen D, Brookes A, Sanseau P, Polinsky RJ, Wasco W, Da Silva HA, Haines JL, Perkicak-Vance MA, Tanzi RE, Roses AD, Fraser PE, Rommens JM, St George-Hyslop PH: Cloning of a gene bearing missense mutations in early-onset familial Alzheimer's disease. Nature 1995, 375:754-760.

28. Rogaev El, Sherrington R, Rogaeva EA, Levesque G, Ikeda M, Liang Y, Chi H, Lin C, Holman K, Tsuda T, et al: Familial Alzheimer's disease in kindreds with missense mutations in a gene on chromosome 1 related to the Alzheimer's disease type 3 gene. Nature 1995, 376:775-778.

29. Chen F, Hasegawa H, Schmitt-Ulms G, Kawarai T, Bohm C, Katayama T, Gu Y, Sanjo N, Glista M, Rogaeva E, Wakutani Y, Pardossi-Piquard R, Ruan X, Tandon A, Checler F, Marambaud P, Hansen K, Westaway D, St GeorgeHyslop P, Fraser P: TMP21 is a presenilin complex component that modulates gamma-secretase but not epsilon-secretase activity. Nature 2006, 440:1208-1212.

30. De Strooper B: Aph-1, Pen-2, and Nicastrin with Presenilin generate an active gamma-Secretase complex. Neuron 2003, 38:9-12.

31. Wolfe MS, Xia W, Ostaszewski BL, Diehl TS, Kimberly WT, Selkoe DJ: Two transmembrane aspartates in presenilin-1 required for presenilin endoproteolysis and gamma-secretase activity. Nature 1999, 398:513-517.

32. Dries DR, Yu G: Assembly, maturation, and trafficking of the gammasecretase complex in Alzheimer's disease. Curr Alzheimer Res 2008, 5:132-146.

33. Nishimura MYG, St George-Hyslop PH: Biology of presenilins as causative molecules for Alzheimer disease. Clin Genet 1999, 55:7.

34. Fraser PE, Yang DS, Yu G, Levesque L, Nishimura M, Arawaka S, Serpell LC, Rogaeva E, St George-Hyslop P: Presenilin structure, function and role in Alzheimer disease. Biochim Biophys Acta 2000, 1502:1-15.

35. Yu G, Nishimura M, Arawaka S, Levitan D, Zhang L, Tandon A, Song YQ, Rogaeva E, Chen F, Kawarai T, Supala A, Levesque L, Yu H, Yang DS, Holmes E, Milman P, Liang Y, Zhang DM, Xu DH, Sato C, Rogaev E, Smith M, Janus C, Zhang Y, Aebersold R, Farrer LS, Sorbi S, Bruni A, Fraser P, St GeorgeHyslop P: Nicastrin modulates presenilin-mediated notch/glp-1 signal transduction and betaAPP processing. Nature 2000, 407:48-54

36. Li Y, Lu SH, Tsai CJ, Bohm C, Qamar S, Dodd RB, Meadows W, Jeon A, McLeod A, Chen F, Arimon M, Berezovska O, Hyman BT, Tomita T, Iwatsubo T, Johnson CM, Farrer LA, Schmitt-Ulms G, Fraser PE, St George-Hyslop PH: Structural interactions between inhibitor and substrate docking sites give insight into mechanisms of human PS1 complexes. Structure 2014, 22:125-135.

37. Thinakaran G, Borchelt DR, Lee MK, Slunt HH, Spitzer L, Kim G, Ratovitsky T, Davenport F, Nordstedt C, Seeger M, Hardy J, Levey Al, Gandy SE, Jenkins NA, Copeland NG, Price DL, Sisodia SS: Endoproteolysis of presenilin 1 and accumulation of processed derivatives in vivo. Neuron 1996, 17:181-190.

38. Weihofen A, Binns K, Lemberg MK, Ashman K, Martoglio B: Identification of signal peptide peptidase, a presenilin-type aspartic protease. Science 2002, 296:2215-2218.

39. Martoglio B, Golde TE: Intramembrane-cleaving aspartic proteases and disease: presenilins, signal peptide peptidase and their homologs. Hum Mol Genet 2003, 12(2):R201-206

40. Friedmann E, Lemberg MK, Weihofen A, Dev KK, Dengler U, Rovelli G, Martoglio B: Consensus analysis of signal peptide peptidase and homologous human aspartic proteases reveals opposite topology of catalytic domains compared with presenilins. J Biol Chem 2004, 279:50790-50798

41. Fluhrer $\mathrm{R}$, Steiner $\mathrm{H}$, Haass $\mathrm{C}$ : Intramembrane proteolysis by signal peptide peptidases: a comparative discussion of GXGD-type aspartyl proteases. J Biol Chem 2009, 284:13975-13979.

42. Lu SH, Jeon AH, Schmitt-Ulms G, Qamar S, Dodd R, McDonald B, Li Y, Meadows W, Cox K, Bohm C, Chen F, Fraser P, George-Hyslop PS: Vigilin interacts with signal peptide peptidase. Proteome Sci 2012, 10:33.

43. De Strooper B, Annaert W: Novel research horizons for presenilins and gamma-secretases in cell biology and disease. Annu Rev Cell Dev Biol 2010, 26:235-260.

44. Steiner $H$, Fluhrer $R$, Haass $C$ : Intramembrane proteolysis by gammasecretase. J Biol Chem 2008, 283:29627-29631. 
45. Podlisny MB, Citron M, Amarante P, Sherrington R, Xia W, Zhang J, Diehl T, Levesque G, Fraser P, Haass C, Koo EH, Seubert P, St George-Hyslop P, Teplow $D B$, Selkoe DJ: Presenilin proteins undergo heterogeneous endoproteolysis between Thr291 and Ala299 and occur as stable N- and C-terminal fragments in normal and Alzheimer brain tissue. Neurobiol Dis 1997, 3:325-337.

46. Laudon $\mathrm{H}$, Hansson EM, Melen K, Bergman A, Farmery MR, Winblad B, Lendahl U, von Heijne G, Naslund J: A nine-transmembrane domain topology for presenilin 1. J Biol Chem 2005, 280:35352-35360.

47. Oh YS, Turner RJ: Topology of the C-terminal fragment of human presenilin 1. Biochemistry 2005, 44:11821-11828.

48. Wolfe MS: Toward the structure of presenilin/gamma-secretase and presenilin homologs. Biochim Biophys Acta 1828, 2013:2886-2897.

49. Doan A, Thinakaran G, Borchelt DR, Slunt HH, Ratovitsky T, Podlisny M, Selkoe DJ, Seeger M, Gandy SE, Price DL, Sisodia SS: Protein topology of presenilin 1. Neuron 1996, 17:1023-1030.

50. Watanabe N, Image I II, Takagi S, Tominaga A, Image Image I, Tomita T, Iwatsubo T: Functional analysis of the transmembrane domains of presenilin 1: participation of transmembrane domains 2 and 6 in the formation of initial substrate-binding site of gamma-secretase. J Biol Chem 2010, 285:19738-19746.

51. Sobhanifar S, Schneider B, Lohr F, Gottstein D, Ikeya T, Mlynarczyk K, Pulawski W, Ghoshdastider U, Kolinski M, Filipek S, Guntert P, Bernhard F, Dotsch V: Structural investigation of the C-terminal catalytic fragment of presenilin 1. Proc Natl Acad Sci U S A 2010, 107:9644-9649.

52. Li X, Dang S, Yan C, Gong X, Wang J, Shi Y: Structure of a presenilin family intramembrane aspartate protease. Nature 2013, 493:56-61.

53. Zhang YW, Luo WJ, Wang H, Lin P, Vetrivel KS, Liao F, Li F, Wong PC, Farquhar MG, Thinakaran G, Xu H: Nicastrin is critical for stability and trafficking but not association of other presenilin/gamma-secretase components. J Biol Chem 2005, 280:17020-17026.

54. Shirotani K, Edbauer D, Capell A, Schmitz J, Steiner H, Haass C: Gamma-secretase activity is associated with a conformational change of nicastrin. J Biol Chem 2003, 278:16474-16477.

55. Spasic D, Raemaekers T, Dillen K, Declerck I, Baert V, Serneels L, Fullekrug J Annaert W: Rer1p competes with APH-1 for binding to nicastrin and regulates gamma-secretase complex assembly in the early secretory pathway. J Cell Biol 2007, 176:629-640.

56. Chen F, Yu G, Arawaka S, Nishimura M, Kawarai T, Yu H, Tandon A, Supala A, Song YQ, Rogaeva E, Milman P, Sato C, Yu C, Janus C, Lee J, Song L, Zhang L, Fraser PE, St George-Hyslop PH: Nicastrin binds to membrane-tethered Notch. Nat Cell Biol 2001, 3:751-754.

57. Shah S, Lee SF, Tabuchi K, Hao YH, Yu C, Laplant Q, Ball H, Dann CE 3rd, Sudhof T, Yu G: Nicastrin Functions as a gamma-Secretase-Substrate Receptor. Cell 2005, 122:435-447

58. Bergman A, Laudon H, Winblad B, Lundkvist J, Naslund J: The extreme C terminus of presenilin 1 is essential for gamma-secretase complex assembly and activity. J Biol Chem 2004, 279:45564-45572.

59. Fagan R, Swindells M, Overington J, Weir M: Nicastrin, a presenilin-interacting protein, contains an aminopeptidase/transferrin receptor superfamily domain. Trends Biochem Sci 2001, 26:213-214.

60. Lu P, Bai XC, Ma D, Xie T, Yan C, Sun L, Yang G, Zhao Y, Zhou R, Scheres SH, Shi $Y$ : Three-dimensional structure of human gamma-secretase. Nature 2014, 512:166-170.

61. Xie T, Yan C, Zhou R, Zhao Y, Sun L, Yang G, Lu P, Ma D, Shi Y: Crystal structure of the gamma-secretase component nicastrin. Proc Natl Acad Sci U S A 2014, 111:13349-13354.

62. Zhang X, Hoey RJ, Lin G, Koide A, Leung B, Ahn K, Dolios G, Paduch M, Ikeuchi T, Wang R, Li YM, Koide S, Sisodia SS: Identification of a tetratricopeptide repeatlike domain in the nicastrin subunit of gamma-secretase using synthetic antibodies. Proc Natl Acad Sci U S A 2012, 109:8534-8539.

63. Fluhrer R, Kamp F, Grammer G, Nuscher B, Steiner H, Beyer K, Haass C: The Nicastrin ectodomain adopts a highly thermostable structure. Biol Chem 2011, 392:995-1001.

64. Zhao G, Liu Z, llagan MX, Kopan R: Gamma-secretase composed of PS1/ Pen2/Aph1a can cleave notch and amyloid precursor protein in the absence of nicastrin. J Neurosci 2010, 30:1648-1656.

65. Francis R, McGrath G, Zhang J, Ruddy DA, Sym M, Apfeld J, Nicoll M, Maxwell M, Hai B, Ellis MC, Parks AL, Xu W, Li J, Gurney M, Myers RL, Himes CS, Hiebsch R, Ruble C, Nye JS, Curtis D: aph-1 and pen-2 are required for Notch pathway signaling, gamma- secretase cleavage of betaAPP, and presenilin protein accumulation. Dev Cell 2002, 3:85-97.
66. Crystal AS, Morais VA, Pierson TC, Pijak DS, Carlin D, Lee VM, Doms RW: Membrane topology of gamma-secretase component PEN-2. J Biol Chem 2003, 278:20117-20123.

67. Watanabe N, Tomita T, Sato C, Kitamura T, Morohashi Y, Iwatsubo T: Pen-2 is incorporated into the gamma-secretase complex through binding to transmembrane domain 4 of presenilin 1. J Biol Chem 2005, 280:41967-41975.

68. Kim SH, Sisodia SS: A sequence within the first transmembrane domain of PEN-2 is critical for PEN-2-mediated endoproteolysis of presenilin 1. J Biol Chem 2005, 280:1992-2001.

69. Kim SH, Sisodia SS: Evidence that the "NF" motif in transmembrane domain 4 of presenilin 1 is critical for binding with PEN-2.J Biol Chem 2005, 280:41953-41966.

70. Prokop S, Shirotani K, Edbauer D, Haass C, Steiner H: Requirement of PEN-2 for stabilization of the presenilin $\mathrm{N}$-/C-terminal fragment heterodimer within the gamma-secretase complex. J Biol Chem 2004, 279:23255-23261.

71. Holmes O, Paturi S, Selkoe DJ, Wolfe MS: Pen-2 is essential for gammasecretase complex stability and trafficking but partially dispensable for endoproteolysis. Biochemistry 2014, 53:4393-4406.

72. Serneels L, Van Biervliet J, Craessaerts K, Dejaegere T, Horre K, Van Houtvin T, Esselmann H, Paul S, Schafer MK, Berezovska O, Hyman BT, Sprangers B, Sciot R, Moons L, Jucker M, Yang Z, May PC, Karran E, Wiltfang J, D'Hooge R, De Strooper B: gamma-Secretase heterogeneity in the Aph1 subunit: relevance for Alzheimer's disease. Science 2009, 324:639-642.

73. Lee SF, Shah S, Yu C, Wigley WC, Li H, Lim M, Pedersen K, Han W, Thomas P, Lundkvist J, Hao YH, Yu G: A conserved GXXXG motif in APH-1 is critical for assembly and activity of the gamma-secretase complex. J Biol Chem 2004, 279:4144-4152.

74. Fortna RR, Crystal AS, Morais VA, Pijak DS, Lee VM, Doms RW: Membrane topology and nicastrin-enhanced endoproteolysis of APH-1, a component of the gamma-secretase complex. J Biol Chem 2004 279:3685-3693.

75. Pardossi-Piquard R, Yang SP, Kanemoto S, Gu Y, Chen F, Bohm C, Sevalle J, Li T, Wong PC, Checler F, Schmitt-Ulms G, St George-Hyslop P, Fraser PE: $\mathrm{APH} 1$ polar transmembrane residues regulate the assembly and activity of presenilin complexes. J Biol Chem 2009, 284:16298-16307.

76. Gu Y, Sanjo N, Chen F, Hasegawa H, Petit A, Ruan X, Li W, Shier C, Kawarai T, Schmitt-Ulms G, Westaway D, St George-Hyslop P, Fraser PE: The presenilin proteins are components of multiple membrane-bound complexes that have different biological activities. J Biol Chem 2004, 279:31329-31336.

77. Mao G, Cui MZ, Li T, Jin Y, Xu X: Pen-2 is dispensable for endoproteolysis of presenilin 1, and nicastrin-Aph subcomplex is important for both gamma-secretase assembly and substrate recruitment. J Neurochem 2012, 123:837-844.

78. Lee SF, Shah S, Li H, Yu C, Han W, Yu G: Mammalian APH-1 interacts with presenilin and nicastrin and is required for intramembrane proteolysis of amyloid-beta precursor protein and Notch. J Biol Chem 2002, 277:45013-45019.

79. Renzi F, Zhang X, Rice WJ, Torres-Arancivia C, Gomez-Llorente Y, Diaz R, Ahn K, Yu C, Li YM, Sisodia SS, Ubarretxena-Belandia I: Structure of gammasecretase and its trimeric pre-activation intermediate by single-particle electron microscopy. J Biol Chem 2011, 286:21440-21449.

80. Lazarov VK, Fraering PC, Ye W, Wolfe MS, Selkoe DJ, Li H: Electron microscopic structure of purified, active gamma-secretase reveals an aqueous intramembrane chamber and two pores. Proc Natl Acad Sci U S A 2006, 103:6889-6894.

81. Osenkowski P, Li H, Ye W, Li D, Aeschbach L, Fraering PC, Wolfe MS, Selkoe DJ: Cryoelectron microscopy structure of purified gamma-secretase at 12 A resolution. J Mol Biol 2009, 385:642-652.

82. Ogura T, Mio K, Hayashi I, Miyashita H, Fukuda R, Kopan R, Kodama T, Hamakubo T, Iwatsubo T, Tomita T, Sato C: Three-dimensional structure of the gamma-secretase complex. Biochem Biophys Res Commun 2006, 343:525-534.

83. Wang $Y$, Maegawa $S$, Akiyama $Y, H a$ Y: The role of $L 1$ loop in the mechanism of rhomboid intramembrane protease GlpG. J Mol Biol 2007 374:1104-1113.

84. Bondar AN, del Val C, White SH: Rhomboid protease dynamics and lipid interactions. Structure 2009, 17:395-405.

85. Lu P, Bai XC, Ma D, Xie T, Yan C, Sun L, Yang G, Zhao Y, Zhou R, Scheres SH, Shi $Y$ : Three-dimensional structure of human gammasecretase. Nature 2014. 
86. Fraering PC, LaVoie MJ, Ye W, Ostaszewski BL, Kimberly WT, Selkoe DJ, Wolfe MS: Detergent-dependent dissociation of active gamma-secretase reveals an interaction between Pen-2 and PS1-NTF and offers a model for subunit organization within the complex. Biochemistry 2004, 43:323-333.

87. Barthet G, Shioi J, Shao Z, Ren Y, Georgakopoulos A, Robakis NK: Inhibitors of gamma-secretase stabilize the complex and differentially affect processing of amyloid precursor protein and other substrates. FASEB $J$ 2011, 25:2937-2946.

88. Miyashita H, Maruyama Y, Isshiki H, Osawa S, Ogura T, Mio K, Sato C, Tomita T, Iwatsubo T: Three-dimensional structure of the signal peptide peptidase. J Biol Chem 2011, 286:26188-26197.

doi:10.1186/1750-1326-9-59

Cite this article as: Li et al:: Structural biology of presenilin 1 complexes. Molecular Neurodegeneration 2014 9:59.

\section{Submit your next manuscript to BioMed Central and take full advantage of:}

- Convenient online submission

- Thorough peer review

- No space constraints or color figure charges

- Immediate publication on acceptance

- Inclusion in PubMed, CAS, Scopus and Google Scholar

- Research which is freely available for redistribution 